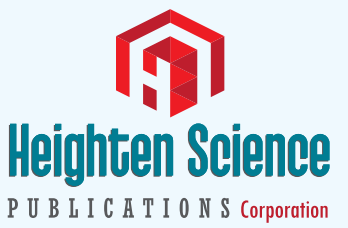

ISSN

2577-140X
*Address for Correspondence: Ejaz Ansari, Department of Ophthalmology, Eye Ear and Mouth Unit, Maidstone \& Tunbridge Wells NHS Trust, Maidstone ME16 9QQ, UK, Tel/Fax: +1622 226275; Email: e.ansari@nhs.net

Submitted: 16 August 2017

Approved: 19 September 2017

Published: 20 September 2017

Copyright: @ 2017 Ansari EA, et al. This is an open access article distributed under the Creative Commons Attribution License, which permits unrestricted use, distribution, and reproduction in any medium, provided the original work is properly cited.

Keywords: Age-related macular degeneration (ARMD); Glaucoma; Ocular hypertension; Ranibizumab/Lucentis; Intraocular pressure; Intravitreal injection; Anti-VEGF
Research Article

\section{Intravitreal Ranibizumab/ Lucentis (IVTL) injections in Glaucoma patients-Intraocular Pressure (IOP) elevation and the use of Anterior Chamber Paracentesis (ACP)}

\author{
EA Ansari ${ }^{1,2 *}$ and H Huraira ${ }^{1}$ \\ ${ }^{1}$ Maidstone \& Tunbridge Wells NHS Trust, UK \\ 2Institute of Medical Sciences, Christ Church College University, Canterbury, UK
}

\section{Abstract}

\section{Purpose}

- To assess the short term effects of intravitreal Lucentis (IVTL) on intraocular pressure in patients with ocular hypertension and glaucoma

- To determine rate of anterior chamber paracentesis (ACP) required post-injection according to departmental protocol

\section{Methods}

This was a prospective, observational study carried out between August 2011 and February 2012 in the Department of Ophthalmology, Maidstone Hospital. 24 participants (13 female, 11 male) with established ocular hypertension (OHT) or glaucoma were chosen from a cohort of patients receiving intravitreal (IVTL) Ranibizumab (Lucentis) treatment for wet age related macular degeneration (WARMD). Apraclonidine $1 \%$ was given pre-injection, and baseline IOP was measured $30 \mathrm{~min}$. after this, just before IVTL. IOP was measured at baseline, within $1 \mathrm{~min}$ of injection, $5 \mathrm{~min}, 15 \mathrm{~min}, 30 \mathrm{~min}$ up to $60 \mathrm{~min}$ following a single IVTL treatment.

Anterior paracentesis was performed if:

- Immediate post injection $\mathrm{IOP}>50 \mathrm{~mm} \mathrm{Hg}$ and $\mathrm{OHT}$

- Immediate post injection IOP $>40 \mathrm{~mm} \mathrm{Hg}$ and there was evidence of disc damage only

- Immediate post injection IOP $>30 \mathrm{~mm} \mathrm{Hg}$ with evidence of disc damage and visual field loss

\section{Results}

$79.2 \%$ had diagnosed disc damage and visual field loss (glaucoma); $12.5 \%$ had disc damage only (preperimetric glaucoma), whereas the remaining $8.3 \%$ had no evidence of disc damage or visual field loss i.e. ocular hypertension (OHT).

Administration of Apraclonidine $1 \%$ prior to IVTL did not cause a statistically significant IOP reduction in patients with $\mathrm{OHT}$ and glaucoma (paired Student's t-test $\mathrm{P}=0.368$ ). Immediately post injection, mean IOP was $41.54 \mathrm{~mm} \mathrm{Hg}$ (SD $14.1,95 \% \mathrm{Cl} 37.20$ to 45.88 ; Paired $\mathrm{T}$ test results $\mathrm{P}<0.0001$,) which confirmed a statistically significant difference between baseline and immediate post injection IOP.

13 out of $24(58 \%)$ of the study patients required anterior chamber paracentesis (ACP) post IVTL according to our devised protocol. There was no statistically significant difference in baseline IOP between the paracentesis and non-paracentesis groups $(p=0.4)$. The presence of a bleb post injection had no statistically significant bearing on immediate post intravitreal IOP $(p=0.3)$.

ACP performed at $1 \mathrm{~min}$ restored IOP to a safer level at $5 \mathrm{~min}$ in all cases thus treated.

\section{Conclusion}

IVTL appears to cause a significant but transient rise in IOP which is reduced after a mean time of 5 minutes. Although the clinical significance of this IOP spike is still unknown, extreme care must be taken in patients with ocular hypertension and glaucoma particularly those with established disc damage and visual field loss. Apraclonidine $1 \%$ appears to have a limited role in the prophylactic lowering of IOP pre-injection. The authors propose the use of the formulated anterior chamber paracentesis protocol for IOP management in patients with $\mathrm{OHT}$ and glaucoma receiving intravitreal anti-VEGF treatment. 


\section{Introduction}

Vascular endothelial growth factor (VEGF) has been shown to contribute to the pathogenesis of age related macular degeneration (ARMD) and other conditions associated with choroidal neovascularisation (CNV) [1,2]. The use of anti-VEGF agents, e.g. ranibizumab (Lucentis; Novartis Pharm UK Ltd., Frimley, UK) and bevacizumab (Avastin; Genentech Inc), is recognised as effective treatment for these conditions [3]. Bevacizumab is a recombinant humanised monoclonal IgG antibody that acts by inhibiting VEGF, while ranibizumab is a humanised monoclonal antibody Fab fragment (IgG1) $[4,5]$. Ranibizumab is approved by NICE to treat wet ARMD. Bevacizumab is approved for use in colorectal cancer [6] and is also commonly used as an off-label treatment for ARMD [5-7].

Both ranibizumab and bevacizumab are considered safe [7-10], (CATT and IVAN studies). There are many case reports documenting transcient and sustained IOP elevation after intravitreal bevacizumab and ranibizumab [11-14]. In addition, there are larger studies addressing the rate of persistent changes in IOP with intravitreal bevacizumab or ranibizumab injections [15]. This group studied the risk of IOP elevation in patients with and without pre-existing glaucoma and found that the glaucoma group was at a significantly increased risk of sustained IOP elevation following anti-VEGF injections [15].

Although, studies have investigated ways of reducing IOP elevations following antiVEGF injections [16,17], no prospective studies on glaucoma patients are available. Also, the significance of IOP elevations, whether transient or sustained, on the longterm progression of glaucoma is unknown, although animal and human studies purely on high IOP in the past have demonstrated deleterious effects on the optic disc cupping and visual field indices $[18,19]$.

With the knowledge that transient and sustained IOP elevations occur following anti-VEGF injections, and that glaucoma is an independent risk factor for sustained IOP elevations, we prospectively examined the IOP elevation profile following a single IVTL injection for wARMD specifically in patients with pre-existing glaucoma. We also propose arbitrarily a treatment protocol utilising anterior chamber paracentesis (ACP) for IOP elevations in glaucoma patients undergoing anti-VEGF injections according to glaucoma severity.

\section{Methods and Materials}

This was a prospective, observational study carried out between August 2011 and February 2012 in the Department of Ophthalmology, Maidstone Hospital. 24 participants (13 female, 11 male) with established ocular hypertension (OHT) or glaucoma were chosen from a cohort of patients receiving intravitreal (IVTL) Ranibizumab (Lucentis) treatment for wARMD. Severity of ocular hypertension and glaucoma was classified into three categories; disc damage and visual field loss, disc damage only and no disc damage or visual field loss i.e. ocular hypertension (Figure 1).

Within a period of two months prior to their intravitreal treatment, all patients underwent thorough ophthalmological investigations, which included determination of best-corrected Snellen visual acuity, slit lamp and fundal biomicroscopy, optical coherence tomography and fundus fluorescein angiography. OCT and FFA images were analysed by a medical retinal specialist.

On the day of their intravitreal treatment, patients with established glaucoma and ocular hypertension had the following parameters measured; baseline intraocular pressure using the Icare ${ }^{\circledR}$ tonometer, (Tiolat Oy, Helsinki, Finland) optic disc examination using slit lamp biomicroscopy and visual field assessment with Humphrey 
SITA standard 24-2 perimetry. All study patients received Apraclonidine $1 \%$ and IOP was re-measured 30 minutes prior to their intravitreal injection. Patients then received $0.05 \mathrm{~mL}$ of intravitreal Ranibizumab (Lucentis) for treatment of their wet agerelated macular degeneration and it was recorded whether there was presence of a subconjunctival bleb.

Post injection, IOP was measured at the following time intervals; immediately post injection (i.e. within 1 minute), 5 minutes, 15 minutes and 30 minutes. This was continued up to 60 minutes post injection or until the reading was within $5 \mathrm{~mm} \mathrm{Hg}$ of the baseline IOP.

Anterior chamber paracentesis was performed if:

- Immediate post injection IOP $>50 \mathrm{~mm} \mathrm{Hg}$

- Immediate post injection IOP > $40 \mathrm{~mm} \mathrm{Hg}$ and there was evidence of disc damage

- Immediate post injection IOP $>30 \mathrm{~mm} \mathrm{Hg}$ with evidence of disc damage and visual field loss

All cases had pre-treatment with g. Chloramphenicol 0.5\%, Proxymetacaine 1\% and g. Povidone Iodine, one drop of each at 5 minute intervals for $15 \mathrm{~min}$. ACP was performed with a 27 gauge needle on the end of an Insulin syringe, passed horizontally and inferiorly at the corneal limbus.

\section{Statistical Analysis}

The major endpoint of this study was to determine the immediate and short-term effects of intravitreal Ranibizumab injections on intraocular pressure in patients with established ocular hypertension and glaucoma. Analyses were carried out using the XLSTAT add in software for Microsoft Excel® (Addinsoft, USA) for Windows 2000. The $\chi^{2}$ test was used in the comparison of nominally scaled variables whilst we employed the paired student's t-test to compare nominal variables against the mean values of measurement variables. A p-value of less than 0.05 was considered as being statistically significant.

\section{Results}

\section{Patient characteristics}

The clinical profiles of the selected patients are illustrated in table 1 . There was no statistically significant difference in the mean age $(p=0.33)$ or gender $(p=0.32)$ between the three groups.

\section{Classification according to disease severity}

Out of the 24 patients with established ocular hypertension or glaucoma receiving intravitreal treatment, $79.2 \%$ had diagnosed disc damage and visual field loss. $12.5 \%$ had disc damage only whereas the remaining $8.3 \%$ had no evidence of disc damage or visual field loss i.e. ocular hypertension. This is illustrated in figure 1.

\section{The use of Apraclonidine 1\% (lopidine)}

The mean baseline intraocular pressure for all three groups was $16.92 \mathrm{mmHg}$ (range 9 to 28, SD=4.98). Thirty minutes after the administration of apraclonidine $1 \%$ administration, the mean intraocular pressure was $15.71 \mathrm{mmHg}(\mathrm{SD}=4.58)$. The twotailed $\mathrm{P}$ value was 0.3855 indicating that administration of apraclonidine $1 \%$ thirty minutes prior to intravitreal injection of $0.05 \mathrm{~mL}$ did not cause a statistically significant intraocular pressure reduction in patients with ocular hypertension and established glaucoma. 


\begin{tabular}{|c|c|c|c|c|}
\hline Characteristics & OHT group $(\mathrm{N}=2)$ & DD only group $(\mathrm{N}=3)$ & $\begin{array}{l}\text { DD \& VFD group } \\
\qquad(\mathrm{N}=19)\end{array}$ & p value \\
\hline \multicolumn{5}{|l|}{ Patient } \\
\hline Age (in years) & & & & 0.33 \\
\hline Mean & 68.5 & 78.7 & 75.8 & \\
\hline Range & $60-77$ & $73-83$ & $60-91$ & \\
\hline Gender & & & & 0.32 \\
\hline Male & $2(100 \%)$ & $2(66.7 \%)$ & $10(52.6 \%)$ & \\
\hline Female & 0 & $1(33.3 \%)$ & $9(47.4 \%)$ & \\
\hline
\end{tabular}

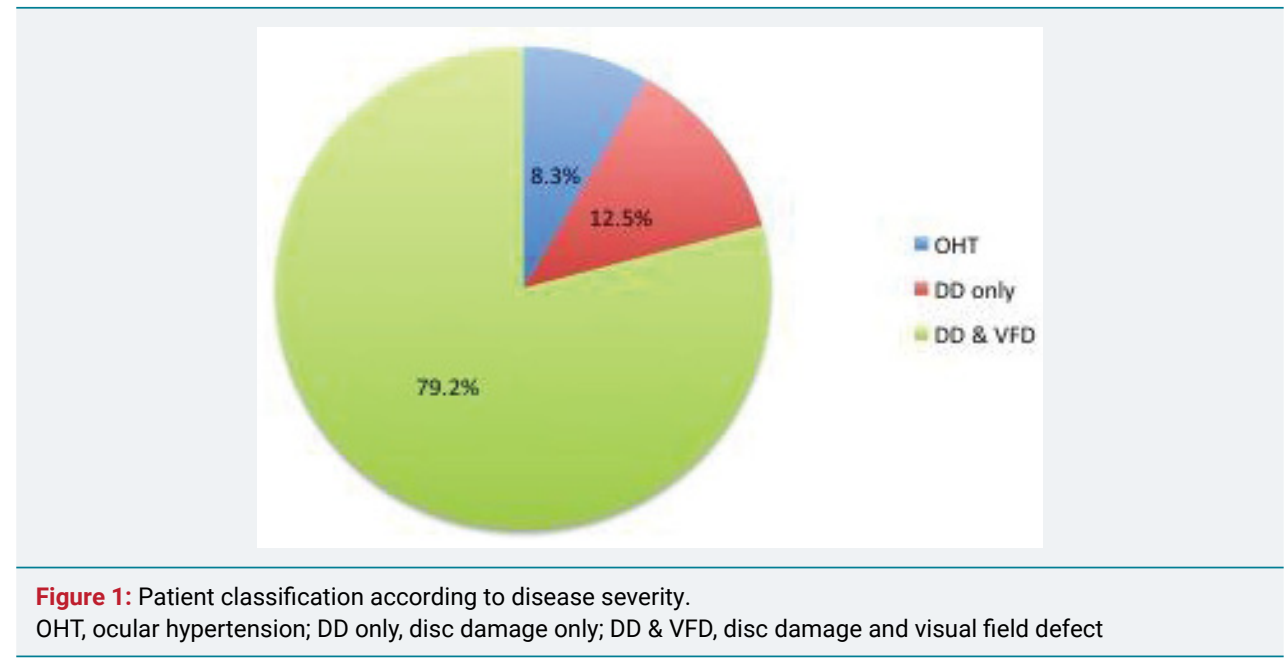

\section{Immediate post injection intraocular pressure}

Immediately post injection, the mean intraocular pressure across the three groups was $41.54 \mathrm{mmHg}(\mathrm{SD}=14.1)$. A two-tailed $\mathrm{p}<0.0001$ confirmed an expected statistically significant difference between the baseline and immediate post injection intraocular pressure.

Table 2 illustrates the mean baseline and immediate post injection intraocular pressure between the three disease severity groups. There was no statistically significant difference in the baseline and immediate post injection intraocular pressure between the three.

\section{Anterior chamber paracentesis}

In accordance with our devised post injection protocol, 14 out of 24 (58.3\%) of our study participants required an anterior paracentesis. There was no statistically significant difference in baseline IOP between the paracentesis and non-paracentesis groups $(\mathrm{p}=0.247)$.

Disease severity appeared to have an influential bearing on whether or not an anterior paracentesis was required with 12 out of the 14 paracentesis patients belonging the established disc damage + visual field defect group. However, the accuracy of this is difficult to ascertain owing to the small sample size (Figure 2).

The mean baseline, immediate post injection and 5 minutes post injection intraocular pressure readings are shown in figure 3 . The data indicates a statistically significant immediate transient rise in intraocular pressure in both the paracentesis and non-paracentesis groups. The pressure spike appears to fall within $5 \mathrm{mmHg}$ of the baseline intraocular pressure in the majority of the study participants after 5 minutes post-injection. ACP performed at $1 \mathrm{~min}$ restored IOP to a safer level at $5 \mathrm{~min}$ in all cases thus treated 


\begin{tabular}{|c|c|c|c|c|}
\hline & $\mathrm{OHT}(\mathrm{N}=2)$ & DD only $(\mathrm{N}=3)$ & DD \& VFD (N=19) & $P$ value \\
\hline $\begin{array}{l}\text { Baseline IOP (in } \\
\text { mmHg) }\end{array}$ & 24 & 14.3 & 16 & $P=0.06$ \\
\hline $\begin{array}{l}\text { Immediate post } \\
\text { injection IOP (in } \\
\mathrm{mmHg} \text { ) }\end{array}$ & 37 & 31.3 & 41.95 & $P=0.379$ \\
\hline
\end{tabular}

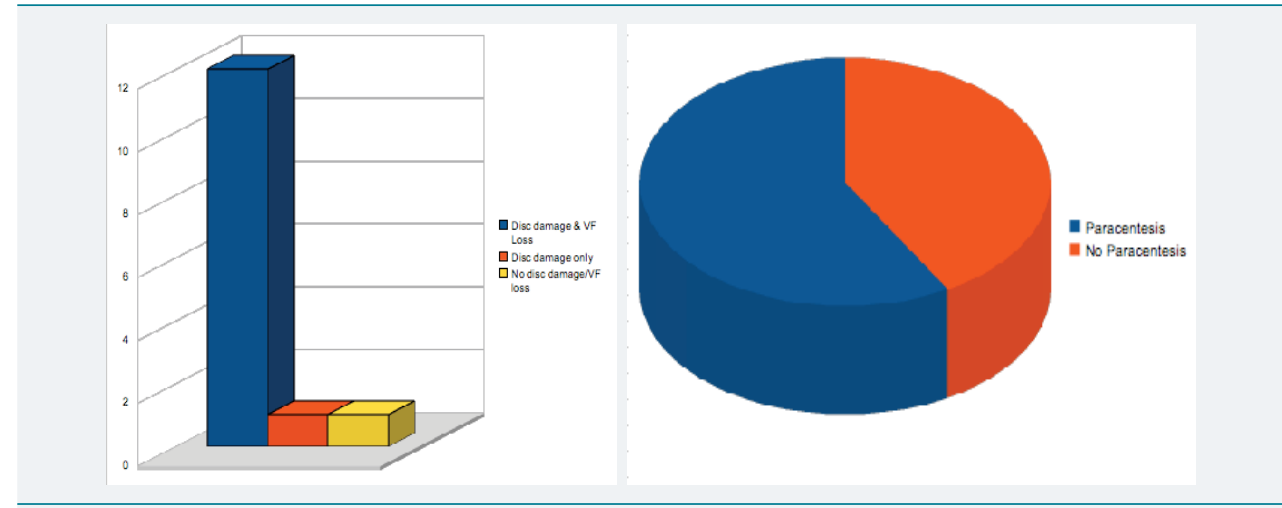

Figure 2: Patients requiring anterior chamber paracentesis \& their classification according to disease severity.

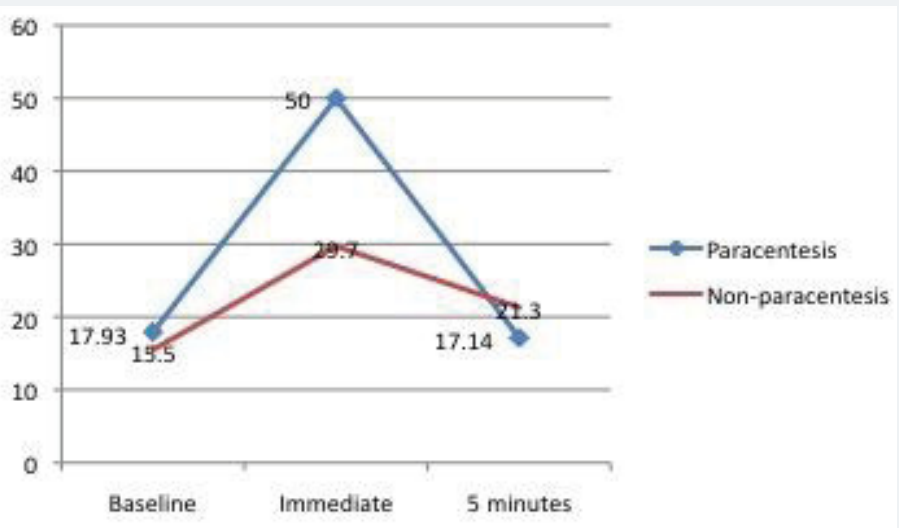

Figure 3: Mean intraocular pressure changes after the intravitreal injection of Ranibizumab (Lucentis)

\section{Bleb presence}

Out of the 24 eyes injected, the presence of a subconjunctival bleb after the intravitreal injection was noted in 4 patients $(16.7 \%)$. There was no statistically significant difference ( $\mathrm{P}$ value 0.95 ) in the immediate post injection intraocular pressure between patients who had a subconjunctival bleb (mean $42 \mathrm{mmHg}$, SD 19.61) and those who did not (mean 41.45mmHg, SD 13.40).

\section{Discussion}

It is most pertinent to note that patients under our care often have multiple ocular co-morbidities, e.g. ARMD and glaucoma. The high volume nature of our wARMD treatment clinics means that other co-morbidities could be overlooked. Glaucoma is one of the commoner conditions and is especially important to note since any situation that leads to poor IOP control can obviously compromise the overall vision [18,19]. Therefore, we must take care not to cause deterioration of one condition whilst trying to treat another.

Studies have demonstrated not only transient but also sustained IOP elevations beyond 1 month in glaucoma patients following anti-VEGF injections [14,15,20-25]. 
This is of great concern since even if the pre-injection glaucoma control is satisfactory (as in our study) this could become compromised after IVTL despite continuation of the same glaucoma treatment, in up to $33 \%$ of patients. Therefore, it is most important to treat any IOP elevations in this group of patients aggressively at the outset, not only to stem the transient IOP spike, but also to prevent sustained increases in IOP.

Therefore, we investigated the IOP elevation prospectively only in patients with glaucoma $(83.5 \%)$ or OHT (16.5\%). The glaucoma group was further sub-divided so that there were 3 groups of patients with differing degrees of disease severity: 1 . ocular hypertension only, 2. established glaucoma with disc damage only, 3. established glaucoma with disc damage and visual field loss.

Pre-treatment with Apraclonidine 1\% did not affect the baseline IOP significantly at $30 \mathrm{~min}$. Results from one study recently were consistent with a significant pretreatment IOP lowering effect, although at $45 \mathrm{~min}$, and not restricted to patients with glaucoma/OHT [17]. Therefore, our study was at odds with previous studies on this matter; it could be related to the relatively smaller sample size, and/or because our cases were exclusively glaucoma/ OHT. One study that agreed with ours found that prophylactic IOP-lowering was not effective in preventing IOP spikes post-injection, and was therefore deemed unnecessary [21]. We maintain that the IOP- lowering effect of pre-treatment with Apraclonidine $1 \%$ in glaucoma patients undergoing antiVEGF injections remains uncertain.

We also investigated whether the presence of vitreous reflux had any significant bearing on the IOP rise following intravitreal Ranibizumab injections. This vitreous reflux/ bleb was observed in $16.7 \%$ of our study subjects although one study reported the as $33 \%$ [26]. Another study concluded that the actual absence of vitreous reflux following intravitreal injections of Ranibizumab or Triamcinolone appeared to be a determining factor in the short-term rise of IOP post injection [27]. From our study results, there was no statistically significant differences in baseline and immediate post injection IOP readings between subjects in which a subconjunctival bleb was noted and those who did not develop one.

Our study looked at the effects of intravitreal Ranibizumab only (Lucentis; Novartis) (IVTL) and therefore, there were no additional confounding factors from the use of other agents, e.g. Bevacizumab (Avastin; Genentec, Inc) which is associated with more frequent IOP elevations, with the possible causes of this having been discussed very elegantly in a previous study [28].

Transient IOP elevations have been reported in various studies that included patients with and without glaucoma $[10,16,17,29]$. In these studies, an IOP elevation of the order of $10 \mathrm{mmHg}$ or more was regarded as significant, probably because it is more than normal diurnal IOP fluctuations [30]. In this study, which concentrated purely on the OHT-glaucoma disease spectrum, the frequency of transient IOP elevation (deemed to require ACP- see figure 3 ) was much higher than in previous studies (58\% v $30 \%$ ). This probably reflects the fact that glaucoma eyes with an already compromised aqueous humour outflow system may be more prone to developing elevated IOP in this setting. The higher mean IOP in this group of patients is an indication that natural fluctuations in eye pressure are not a likely explanation for the observed values.

Based on the frequency and severity of transient and sustained IOP elevations in this group of susceptible eyes, we devised a treatment protocol involving ACP to stem the transient IOP elevation. Although the significance of transient IOP elevations is unknown, we know from previous studies that long-term tight IOP control, particularly in patients with established glaucoma (advanced disc cupping and field defects) is essential to prevent further visual field loss [19,31]. Although patients with normal uncompromised optic discs are able to tolerate short term intraocular pressure 
spikes following procedures such as cataract surgery [32], there is some evidence to suggest that transient IOP spikes in patients with vulnerable optic discs are likely to be detrimental [33-36]. In one electrophysiological study the inner retina of eyes with ocular hypertension had a heightened sensitivity to vascular or mechanical changes induced by transient IOP elevation [37]. Another study on patients with glaucoma undergoing LASIK concluded that it is possible that a small cohort of patients with preexisting glaucomatous optic neuropathy may be more susceptible to transient increase in IOP, although the result needed confirmation with more cases [38].

The mechanisms of sustained elevation of IOP by IVT anti-VEGF remain unknown. However, it may be multifactorial, involving 1) Intraocular injection-related complications, such as mechanical blockage of the trabecular meshwork or Schlemm's canal outflow 2) Drug-induced complications such as trabeculitis or uveitis and cytotoxicity to the trabecular meshwork 3) Patients with pre-existing glaucoma [39]. In a recent meta-analysis, it was also difficult to establish a link between frequency of IVT injections and sustained IOP rise [39], but one randomised controlled trial showed that the frequency of IOP elevation following IVT Aflibercept (which is injected less frequently) was lower than IVT Ranibizumab [40].

There are limitations and weaknesses of our study. The small sample size has a bearing on the statistical accuracy of the interpreted results. However, our results on the whole appeared to be in concordance with similar larger studies. In addition, this study did not take into consideration which stage of anti-VEGF treatment the patients were in or whether they had already received previous intravitreal treatment for their wet age related macular degeneration.

In summary, patients receiving intravitreal anti-VEGF treatment for wet age related macular degeneration benefit greatly from the unprecedented central vision gains in a disease, which was previously deemed untreatable. However, patients with pre-existing conditions in which the optic nerve is vulnerable, are at risk of developing further optic disc damage due to the intraocular pressure spikes after intravitreal procedures. These patients are also at a higher risk of developing sustained elevated IOP and further glaucoma-related loss of vision.

The current study confirms and adds to the data related to the growing number of cases of IOP elevation in patients receiving intravitreal anti-VEGF injections. It demonstrates that eyes with glaucoma have a higher frequency of IOP elevation in this setting, that pre-treatment with Apraclonidine 1\% is of limited value in preventing this, but anterior chamber paracentesis (ACP) is a safe and very effective method for reducing the IOP to a safe level quickly. It is also quick to perform so that it does not add any additional time to the treatment procedure and does not add any significant risks to the patient. None of our cases of ACP had problems such as endophthamitis or hypotony or corneal decompensation.

Although our study was prospective in a real-world setting, advocating the routine use of ACP in this situation is not possible because of the small sample size. This study is being continued to include more cases, and further prospective studies are required to investigate whether or not the visual field indices and optic disc/ retinal nerve fibre layer in these cases deteriorate more than matched cases of glaucoma not undergoing IVTL.

\section{References}

1. Kvanta A, Algvere PV, Berglin L, Seregard S. Subfoveal fibrovascular membranes in age related macular degeneration express vascular endothelial growth factor. Invest Ophthalmol Vis Sci. 1996; 37: 1929-1934. Ref.: https://goo.gl/1thLnq

2. Shams $\mathrm{N}$, lanchulev $\mathrm{T}$. Role of vascular endothelial growth factor in ocular angiogenesis. Ophthalmol Clin North Am. 2006; 19: 335-344. Ref.: https://goo.gl/Wu4JFG 
3. Bressler SB. Introduction: understanding the role of angiogenesis and antiangiogenic agents in agerelated macular degeneration. Ophthalmology. 2009; 116: S1-S7. Ref.: https://goo.gl/Ffvuky

4. Package insert. Avastin (Bevacizumab). San Francisco: Genentech, 2004.

5. Package insert. Lucentis (Ranibizumab). San Francisco: Genentech, 2006

6. Zondor SD, Medina PJ. Bevacizumab: an angiogenesis inhibitor with efficacy in colorectal and other malignancies. Ann Pharmacother. 2004; 38: 1258-1264. Ref.: https://goo.gl/ez9Qk8

7. Bressler NM. Antiangiogenic approaches to age-related macular degeneration today. Ophthalmology 2009; 116: S15-S23. Ref.: https://goo.gl/MWv72s

8. Rich RM, Rosenfeld PJ, Puliafito CA. Short-term safety and efficacy of intravitreal bevacizumab (Avastin) for neovascular age-related macular degeneration. Retina. 2006; 26: 495-511. Ref.: https://goo.gl/5RCmZv

9. Fung $A E$, Rosenfeld $P J$, Reichel $E$. The International intravitreal bevacizumab safety survey: using the internet to assess drug safety worldwide. $\mathrm{Br} \mathrm{J}$ Ophthalmol. 2006; 90: 1344-1349. Ref.: https://goo.gl/3u7tYn

10. Gordon A, Maximiliano M. Bevacizumab local complications. Ophthalmology. 2009; 116: 2264. Ref.: https://goo.gl/utdoR4

11. Jalil A, Fenerty C, Charles S. Intravitreal bevacizumab (Avastin) causing acute glaucoma: an unreported complication. Eye (Lond). 2007; 21: 1541. Ref.: https://goo.gl/PfJa8j

12. Zheng $\mathrm{Q}$, Mayer $\mathrm{H}$, Adelman RA. Persistent ocular hypertension following multiple intravitreal AntiVEGF Injections for AMD. Invest Ophthalmol Vis Sci. 2009; 50: 959. Ref.: https://goo.gl/GVLoHd

13. Bakri SJ, McCannel CA, Edwards AO. Persistent ocular hypertension following intravitrea ranibizumab. Graefes Arch Clin Exp Ophthalmol. 2008; 246: 955-958. Ref.: https://goo.gl/wwEcRJ

14. Kahook MY, Kimura AE, Wong LS. Sustained elevation of intraocular pressure associated with intravitreal bevacizumab injections. Ophthalmic Surg Lasers Imaging. 2009; 40: 293-295. Ref.: https://goo.gl/WznkVq

15. Good TJ, Kimura AE, Mandava N, Kahook MY. Sustained elevation of intraocular pressure after intravitreal injections of anti-VEGF agents. $\mathrm{Br} \mathrm{J}$ Ophthalmol. 2011; 95: 1111-1114. Ref.: https://goo.gl/2Fc6GL

16. Rashid A, Quhill F, Pushpoth S. Effect of lopidine administration prior to intravitreal Lucentis injection on intraocular pressure spike. Invest Ophthalmol Vis Sci. 2009; 50. Ref.: https://goo.gl/N9LQN1

17. El Chehab H, Le Corre A, Giraud JM. Efficacy of prophylactic treatment of intraocular pressure spikes due to intravitreal injections. J Fr Ophtalmol. 2012; 35: 614-621. Ref.: https://goo.gl/ovKRSE

18. Fortune B, Burgoyne CF, Cull GA. Structural and functional abnormalities of retinal ganglion cells measured in vivo at the onset of optic nerve head surface change in experimental glaucoma. Invest Ophthalmol Vis Sci. 2012; 53: 3939-3950. Ref.: https://goo.gl/JpYkWP

19. The Advanced Glaucoma Intervention Study (AGIS): 7. The Relationship Between Control of Intraocular Pressure and Visual Field Deterioration THE AGIS INVESTIGATORS. Am J Ophthalmol. 2000; 130: 429-440. Ref.: https://goo.gl/thpmvq

20. Carver J, Bouska C, Corey R. Avastin and risk of glaucoma [abstract]. New York: Retina Congress, 2009.

21. Frenkel MP, Haji SA, Frenkel RE. Effect of prophylactic intraocular pressure lowering medication on intraocular spikes after intravitreal injections. Arch Ophthalmol. 2010; 128: 1523-1527. Ref.: https://goo.gl/G2YmUr

22. Kim JE, Mantravadi AV, Hur EY, Covert DJ. Short term intraocular pressure changes immediately after intravitreal injections of anti-vascular endothelial growth factor agents. Am J Ophthalmol. 2008; 146: 930-934. Ref.: https://goo.gl/Tey8J2

23. Hollands $H$, Wong J, Bruen R, Campbell RJ, Sharma S. Short-term intraocular pressure changes after intravitreal injection of bevacizumab. Can J Ophthalmol. 2007; 42: 807-811. Ref. https://goo.gl/iUWVVg

24. Sharei V, Hohn F, Kohler T, Hattenbach LO, Mirshahi A. Course of intraocular pressure after intravitreal injection of $0.05 \mathrm{~mL}$ ranibizumab (Lucentis). Eur J Ophthalmol. 2010; 20: 174-179. Ref.: https://goo.gl/15oqcJ 
25. Gismondi M, Salati C, Salvetat ML, Zeppieri M, Brusini P. Short-term effect of intravitreal injection of Ranibizumab (Lucentis) on intraocular pressure. J Glaucoma. 2009; 18: 658-661. Ref.: https://goo.gl/9ZNRnV

26. Usman SM, Batra R, Qureshi F, Clark D. Reflux of drug during intravitreal anti-VEGF therapies. Semin Ophthalmol. 2011; 26: 357-360. Ref.: https://goo.gl/Dbng6T

27. Arikan G, Osman SA, Hakan OF. Immediate intraocular pressure rise after intravitreal injection of ranibizumab and two doses of triamcinolone acetonide. Int $\mathrm{J}$ of Ophthal. 2011; 4: 402-405. Ref.: https://goo.gl/iy8jj2

28. Kahook MY, Liu L, Ruzycki P. High-molecular-weight aggregates in repackaged bevacizumab. Retina. 2010; 30: 887-892. Ref.: https://goo.gl/9B4iji

29. Nabili S, Stevenson M, Chakravarty U. Short-term effect of intravitreal anti-VEGFs delivery on intraocular pressure. Br J Ophthalmol. 2009; 93: 552-553. Ref.: https://goo.gl/1By6KZ

30. Drance SM. The significance of the diurnal tension variations in normal and glaucomatous eyes. Arch Ophthalmol. 960; 64: 494-501. Ref.: https://goo.gl/XHdVi7

31. Stewart WC, Chorak RP, Hunt HH, Sethuraman G. Factors associated with visual loss in patients with advanced glaucomatous changes in the optic nerve head. Am J Ophthalmol. 1993; 116: 176-181. Ref.: https://goo.gl/FhSTBx

32. Tranos $P$, Bhar G, Little B. Postoperative intraocular pressure spikes: the need to treat. Eye(Lond) 2004: 673-679. Ref.: https://goo.gl/aBbJcp

33. Buono LM, Foroozan R, Sergott RC, Savino PJ. Nonarteritic anterior ischemic optic neuropathy. Curr Opin Ophthalmol. 2002; 13: 357-361. Ref.: https://goo.gl/ugH8z4

34. Basile C, Addabbo G, Montanaro A. Anterior ischemic optic neuropathy and dialysis: role of hypotension and anemia. J Nephrol. 2001; 14: 420-423. Ref.: https://goo.gl/XruK3z

35. Koker AE. Visual prognosis in advanced glaucoma: a comparison of medical and surgical therapy for retention of vision in 101 eyes with advanced glaucoma. Trans Am Ophthalmol Soc. 1977; 75 539-555. Ref.: https://goo.gl/XBLkvi

36. Savage JA, Thomas JV, Belcher III CD. Extracapsular cataract extraction and posterior chamber intraocular lens implantation in glaucomatous eyes. Ophthalmology. 1985; 92: 1506-1516. Ref.: https://goo.gl/aoTPUh

37. Colotto A, Falsini B, Salgarello $T$ et al. Transiently raised intraocular pressure reveals pattern electroretinogram losses in ocular hypertension. Invest Ophthalmol Vis Sci. 1996; 37: 2663-2670. Ref.: https://goo.gl/qRD2U1

38. Chan KC, Poostchi A, Wong $T$ et al. Visual field changes after transient elevation of intraocular pressure in eyes with and without glaucoma. Ophthalmology. 2008; 115: 667-672. Ref.: https://goo.gl/A8J4xv

39. Yandan Zhou, Minwen Zhou, Shigang Xia, et al. Sustained Elevation of Intraocular Pressure Associated with Intravitreal Administration of Anti-vascular Endothelial Growth Factor: A Systematic Review and Meta-Analysis. Sci Rep. 2016; 6: 39301. Ref.: https://goo.gl/cQepW1

40. Freund, K.B, Hoang, Q.V, Saroj N, Thompson D. Intraocular Pressure in Patients with Neovascular AgeRelated Macular Degeneration Receiving Intravitreal Aflibercept or Ranibizumab. Ophthalmology. 2015; 122: 1802-1810. Ref.: https://goo.gl/eoKt2c 